\title{
Improving Students' Educational Experience by Harnessing Digital Technology: elgg in the ODL Environment
}

\author{
Lai Cheng Tung \\ Wawasan Open University, Malaysia
}

\begin{abstract}
Given the rising popularity of both open and distance learning (ODL) and social networking tools, it seems logical to merge and harness these two popular technologies with the goal of improving student educational experience. The integration seems to hold tremendous promise for the open and distance learning mode. To reduce the gap in the literature, this study explores the educational benefits of social media tools on distance learners' perspectives and experiences in an online course taught using elgg (open source social media tool) platforms. To achieve this, the study relied on collecting qualitative and quantitative data from students who were required to use elgg, in addition to LMS, for one semester as part of their coursework. The findings indicated that students enjoyed the social learning experience afforded by the elgg better when compared to LMS to support one another in their distance learning experiences. It was also noted that students, with little experience in social networking and the sharing features on elgg, in most cases, exhibited high involvement in course-related work and graded exercises. Additionally, it was observed that students shared information limited only at the level required by the instruction mode. The study concludes that most students perceived their learning experience was enhanced by their interaction with each other and with the instructors in the elgg. The article ends with a discussion of results and highlighting the areas for future research on the topic.
\end{abstract}

Keywords: ODL; Social networking technology; Student interaction; LMS; elgg; Social learning experience

\section{Introduction}

New technologies that influence how information is created, shared and connected holds promise for education, especially in the Open and Distance Learning (ODL) education mode. Historically, much of online and ODL education has been plagued by issues such as learners' feelings of isolation, a lack of participant interaction from learner-to-learner and from learner-to-instructor, and this may lead to higher dropout rates compared to conventional education (Veletsionos \& Navarrete, 2012). Furthermore, traditionally, distance education has been an educational form with limited possibilities for learners to learn with and from each other. This means that learners' experiences were often reduced to using technology that only, more or less, made it possible for them to download ready-made educational material within the program or course they attended (Olofsson, 2007). Presently, with the emergence of Web 2.0 technologies and the recent popular growth of social networking applications, distance learners have increasing opportunities to 
practice a broader range of 21st-century skills, specifically: collaboration, knowledge sharing and the development of critical thinking skills. As noted by Siemens and Conole (2011) "... the idea of the Internet - distributed, social, networked - influences the structure of education, teaching, and learning". The authors observed that the emergence of new internet technologies has re-made how people communicate and interact with each other and how society creates and shares content with one another. The implications for education are rather significant. The changing technological environment provides new opportunities for teaching and learning focused on the use of social networking sites to create better, more functional learning communities.

General interest in student-centered pedagogies has shifted to the use of social media tools as a replacement of traditional teaching and learning tools in order to enhance student learning. The integration and use of social networking technology as a distance learning platform seems to hold promise (Brady, Holcomb, \& Smith, 2010; Olofsson, 2007; Siemens \& Conole, 2011; Veletsionos \& Navarrete, 2012). Many distance education institutions have traditionally employed Learning Management Systems platform (LMS) and/or Content (Course) Management Systems (CMS) platforms. While generally, LMS and CMS promote a certain amount of information exchange between learners, these suffer from the fact that they do not happen in "real time", they lack the feature of users having an online social presence, fail to support personalization and are very much lesson-focused. Studies on distance education have also shown that learners are more successful in their coursework when they able to develop a sense of community and belonging when they do not get the opportunity to meet and in interact with their peers and instructors (DeSchryver, Misha, Koehler, \& Francis, 2009). Anderson (2005) noted that the key variable interaction in the online learning environment pivots on the role of social presence among the students. The contention is that social presence leads to reduced feelings of detachment while simultaneously encouraging more interaction and participation. Although LMS or CMS are popular in education, newly emerging social networking technology (such as elgg), created specifically for an educational environment, provides another kind of opportunity for distance educators to tap into in order to encourage social presence and facilitate a sense of community among students. A main feature of social networking technology is that it focuses on learners rather than simply on content, which encourages development of a "learning community".

Nevertheless, studies of technological innovations suggest that for technology-rich interventions to be successful, they need to be validated (Doering \& Veletsianos, 2008; Veletsianos, 2010). This study is an attempt to explore the social networking technology to better understand what the social networking technology [i.e. elgg] might afford and evaluate the learners' experiences during the process of elgg mediated learning.

\section{The Application of elgg in Distance Learning}

There is a lack of literature examining social networking media that focuse on student experiences in distance learning courses. However, the few studies that do exist provide much-needed insight on the topic. There are numerous social networking tools that are able to facilitate teaching and learning. Examples of social networking tools that are currently popular among educators are elgg and Ning, but these are by no means the only ones. The impact of such social networking media on learning environments, especially when these are adapted to enhance the breadth and depth 
of information resources as well as the inter-connectivity between learners and instructors, presents an opportunity for instructors to keep learners engaged (Wankel, 2009). Thomas and Thomas (2012) contend that many institutions are resistant to change and view these new networking technologies as a "young-person's game", which is to say, more of an obstacle than an opportunity. Institutions which choose to harness networking technologies will be championed for innovation compared to those who avoid these opportunities. Siemens (2010), in his personal blog, argued that social technology networks might be seen by some as subverting the role of the teacher in the classroom and learning, generally, but in fact, it can make the "classroom walls thinner" or "wall-less". Experts are no longer "out there" or "over there".

Oradini and Saunders (2008), two professors from the University of Westminster, England, presented an evaluation study of the use of a social networking site called My Westminster, powered by elgg, that allows users to create their own profiles, upload photographs and documents, create and join discussion groups, send instant messages, publish blogs and presentations all in one single display. Their study covered all academic employees and students who accessed the system from September 2007 to January 2008. Both quantitative and qualitative data showed that student users, in particular, were split in their opinions about whether the system was useful or not. Commonly, student users commented that the system is invaluable for making new friends and helping connect to their peers for support, particularly when a new semester begins. Other students felt it was helpful and liked it because it was a closed community, which they regarded as better than open public commercial social networking systems like Facebook or MySpace. Academic staff users mostly felt the system helped them and students to build a sense of community and belonging. Like student users, many faculty members felt that they had very little time to use the system.

In a similar study, Veletsianos and Navarrete (2012) sought to identify and understand learners' experiences in an online education technology course facilitated through a social networking platform, elgg, at the University of Texas at Austin, USA. The course ran for the duration of 6weeks. During the course students were required to read their peers' reflections, post questions, and respond to all questions/comments left on their blog. This process was continued and grades were given accordingly at the end of these activities. One thing to note about this study was that students' participation was limited to course-related purposes and students did not seem to mix social and educational participation. They also seemed to have required additional support to manage the expanded amount of information presented to them. Though students indicated networked learning opportunities are promising and cherished the opportunities for interaction, the authors also noted that some students seem to lack skills in managing their learning strategies, such as the ability to find and categorize content for future retrieval and to easily traverse networks of interest.

Dron and Anderson's (2009) findings on employing an elgg platform at the University of Brighton, UK, students enrolled were primarily majoring in computing and digital media programs. According to the researchers, the findings suggested that some students were "lost in social space" and they needed additional support and scaffolding to participate in the social networked learning environment whilst their findings reveal most students' experiences were generally positive. 


\section{Methodology}

The main reasoning behind this study was try to examine the barriers in ODL, find ways to overcome them and find ways to improve and increase distance learners' education experience. This is particularly important when much of online distance education has been plagued by issues such as learners' feelings of isolation and lack of interaction from learner-to-learner and from learner-to-instructor, which in turn, frequently leads to dropping out.

The study was conducted in the January semester of 2013 and all participants in this study were students enrolled in an entry-level undergraduate Human Resource Management course. The author was the course coordinator, and this was the first time that students were given two supportive learning resources, elgg and LMS (WawasanLearn) to facilitate their learning experience. Though the elgg platform was an optional learning platform, students and tutors were given access and encouraged to use the platform concurrently with the use of LMS.

One hundred and eighty (180) students and nine (9) tutors from various regional centers across Malaysia were enrolled and participated in this course.

In order to initiate investigation of whether elgg can potentially benefit learners, while creating personal space for learner-centered exploration and discussion, the course coordinator as well as the tutors would include pointers and activities such as useful bookmarked sites, relevant discussion topics, and debate issues related to the study material to argue for or against a particular thesis in a debate in lieu of responding to their learning. From time to time, the course coordinator's activities would include commenting on student blog entries, occasional alerts that would direct students to particularly noteworthy comments from their peers, and an establishment of an ethos of openness throughout the course by encouraging students to suggest ways to improve it and learn from each other.

At the end of semester, questionnaires (surveys) were distributed to the student participants to gather their perceptions and experiences of using the elgg platform. At the time, the same cohort of students was asked to compare their learning experience with both LMS and elgg.

To this end, the goal of this study is to evaluate the learners' experiences in a distance learning course facilitated through elgg. In particular, the following research questions were posed to the research participants.

- Question \#1: How students perceive the use of an elgg as the learning mechanism through which the course was presented, compared to traditional LMS?

- Question 2: What are the students experiences in a distance learning course taught on a social networking platform?

Methodologically, the researcher used both the qualitative [interpretive] and quantitative research paradigms in this study. In order to ensure validity and reliability, several triangulation methods were used, such as collection of data from multiple sources via survey using both closed 
and open-ended questions, followed by brief interviews for those who agreed for the follow up with face-to-face interview. Qualitative data requires the ability to question, translate, coordinate and determine the viability of the meaning of re-occurring issues and phenomena. Under the interpretive paradigm, a case study method was employed where under the case study methodology the qualitative data collected were analyzed for the emergence of key themes using a coding method by the researcher. The questionnaire was used to collect social demographic data and prior experiences with social media in addition to closed and open-ended questions that sought feedback about students' perceived learning experiences via this platform.

\section{The elgg Platform}

Elgg (http://elgg.org) is an open source framework released under the GNU General Public License (GPL) and is built on LAMP, a platform consisting of Linux, Apache, MySQL, Perl, PHP and Python. The software itself has its own plug-in architecture that enables designers to implement a variety of Web 2.0 tools such as weblog, file repository, social bookmarks, online profile, RSS reader, collaborative document authoring and micro-blogging in a central space for users. Additionally, all users' content can be tagged with keywords so that they can be connected with other users with similar interests. The main distinct feature of elgg is that the user can create a personal learning community such as a "group". Users are able to create personal profiles and create customized "friend" lists, they can post status updates, follow activity streams, and subscribe to be notified of other users' actions within the environment. This is similar to the functionality of Facebook. However, where elgg differs from a regular commercial social network, such as Facebook or MySpace, is the degree of "control" each user is given over who can access their content. Each profile item, blog post, or uploaded file can be assigned its own access restrictions. For instance users can set each file or comment from "fully public" to only readable by a particular group or individual within the community.

The WOU elgg (http://elgg.wou.edu.my/) is a closed platform due to privacy and safety concerns and is hosted by the University network platform strictly for limited users, as this is the first experimental phase. The WOU elgg is the first attempt to explore social networking functionality that aims to improve and enhance student learning in a distance learning environment. On the platform, the student user or the tutor user is required to set-up their personal profile page, where they are able to post to a personal message board things such as status updates, enlisting personal friends, and a personal blog page. Another more personalized feature afforded by elgg is the personal dashboard, in which the user is able to make amendments such as editing or removing the default features according to his or her personal taste or desire. Figure 1 and Figure 2 show a personalized profile page and generic dashboard for all users. 


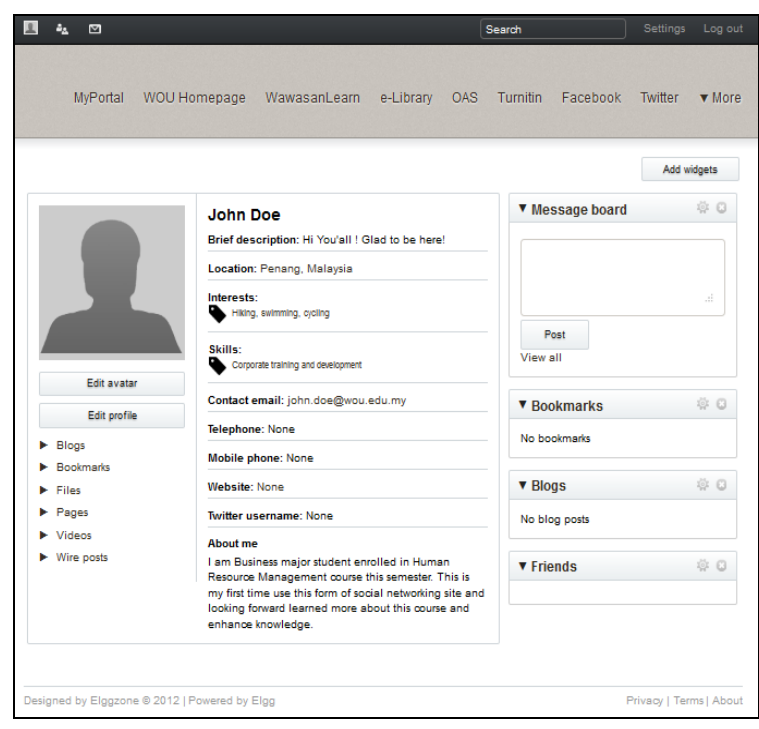

Figure 1. Personalized Profile [sample]

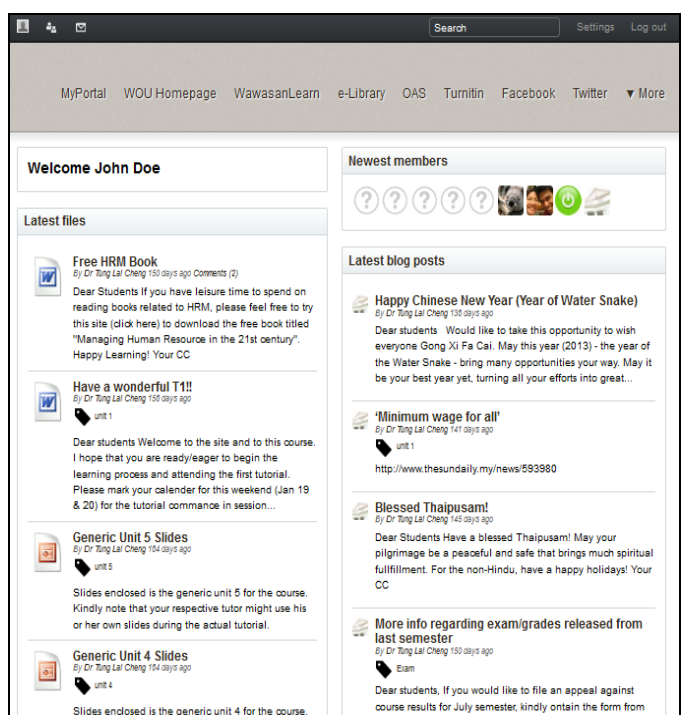

Figure 2. Generic Dashboard [sample]

\section{Findings and Results}

There were one hundred and eighty (180) students and nine (9) tutors who were enrolled in this course and who were encouraged to use elgg concurrently with LMS, only about 89 students and 4 tutors were recorded actively participating in elgg during the course. At the end of the semester, all students and tutors were asked to fill out the voluntary questionnaire that asked about their personal experiences throughout the course. Out of one hundred and eighty (180) students and nine (9) tutors, only 81 students responded to the survey questionnaire and 5 students agreed to participate in a follow up face-to-face brief interview. Four out of nine of the tutors responded to the questionnaires.

Student participant demographics were as follows: forty percent $(40 \%)$ of them were new to the university ( 2 semesters or less) and seventy percent (70\%) of were experienced computer users. Ninety percent $(90 \%)$ were working professional adults who have some or minor knowledge in the field of human resources. All student participants reporting were comfortable using the internet for learning purposes. With regards to the use of social networking technologies in their personal life, eighty percent $(80 \%)$ of the participants reported having an active Facebook account and actively engaged with the platform to communicate with their peers, primarily for social networking purposes. In terms of participating tutors demographics; $80 \%$ were with the University for 4 semesters or more, and all (100\%) tutors rated themselves as experienced computer users. Although only half (50\%) of the tutors participants reported having an active Facebook account, all felt very comfortable using this technology for teaching and learning purposes.

The results of the closed-ended questionnaires were drawn from 5 questions measuring the respondents' attitudes towards internet [especially regarding social networking tools] and constructed learning based on a five-point Likert scale, i.e. 1 (strongly Disagree); 2 (disagree); 3 (neutral), 4 (Agree) and 5 (strongly Agree). 
Table 1 shows the mean scores for each statement regarding attitudes towards the internet via social networking tool use for [teaching and] learning. All five items contained in students' responses to the closed-ended questionnaire had a mean value of more than 3.00 , which mean on the agreeable and positive attitudes tendency. The lowest score (mean $=3.10$ ) was on their perception towards "using the social networking tool to learn about a topic that interested me on my own excites me'. The highest score statement (mean $=3.81$ ) was on their perception of using social networking tool in the classroom can improve person to person interaction. Perhaps, since all of them are adult distance learning students, the social networking tool has helped [in some way] to increase social interaction with their student peers. In terms of tutors' perception and attitudes towards the use of social networking tools in their teaching, the result clearly showed that all four tutor participants were comfortable (mean $=4.0$ ) and have a positive attitude (mean $=4.0$ ) towards the use of technology in teaching. However, they seem to be neutral (mean = 3 ) towards the statement regarding the use of social networking tools in the classroom can improve interaction.

Table 1: Mean and Standard Deviation Scores on Students and Tutors

\begin{tabular}{|c|c|c|c|c|}
\hline \multirow{2}{*}{$\begin{array}{l}\text { Statement } \\
\text { I am comfortable to use the social networking tool for } \\
\text { [teaching and] learning }\end{array}$} & \multicolumn{2}{|c|}{$\begin{array}{l}\text { Student } \\
\mathrm{N}=81\end{array}$} & \multicolumn{2}{|c|}{$\begin{array}{l}\text { Tutor } \\
\mathrm{N}=4\end{array}$} \\
\hline & 3.65 & 0.10 & 4 & 0 \\
\hline $\begin{array}{l}\text { I have a positive attitude towards the use of technology in } \\
\text { [teaching and] learning }\end{array}$ & 3.75 & 0.09 & 4 & 0 \\
\hline $\begin{array}{l}\text { I am interested to use the internet [such as any learning } \\
\text { platform] for personal [ teaching and] learning }\end{array}$ & 3.28 & 0.08 & 3.50 & 0.29 \\
\hline $\begin{array}{l}\text { Using the social networking tool to learn about a topic that } \\
\text { interested me on my own excites me }\end{array}$ & 3.10 & 0.09 & 3.50 & 0.29 \\
\hline $\begin{array}{l}\text { I believe that with the use of social networking tool in } \\
\text { classroom can improve more interaction }\end{array}$ & 3.81 & 0.10 & 3.00 & 0.41 \\
\hline
\end{tabular}

Following to the closed-ended questionnaire, two open-ended questions together with the followup interviews were analyzed regarding the emerging themes about the use of elgg in their personal learning experiences. Although 4 tutor participants voluntarily filled out the closed-ended questions, none of them were interested in responding to the open-ended questions or participating in the personal interview due to various personal reasons. To analyze the openended data, the researcher read through all of the responses to determine themes present in the responses. The themes were reviewed and placed into emerging theme categories as follows:

- Social Interactivity and Connectivity

- Cooperative Learning

- Appreciation of Differences of Opinion 


\section{Social Connectivity and Interactivity}

At the beginning of the course, students were asked to create a personal profile on the elgg that allows them to create an "avatar" by sharing either a photograph of themselves or a cartoon character self-representation; post information about their majors and interests both inside and outside of class; and view one another's profiles to get to know each other. These introductory activities were an attempt to introduce students to one another, in order to establish a social presence. Social presence as defined by Garrison, Anderson, and Archer (2000) is the participants' ability to project their personal characteristics into the online community, thereby presenting themselves to other participants as real people in a distance learning space. Student participants stated that they found great value in their interactions with their peers. For example, one particular participant summarized the whole learning experience as "socially connected and yet interactive enough to help me learn through the course". Also noted by one of the participants interviewed:

"I think that this new learning management [elgg] is more user-friendly and more interactive than the Facebook that I accustomed to as thought I am actually engaging in a face-to-face conversion with my study cohorts in this course... I especially like the avatar feature that I can use my favorite cartoon character to representing me in the site..."

Other respondents mentioned that their interactions with peers was important in helping them make sense of the subject matter, especially by discussing the assignment questions and topics, and they shared that the experience of interacting through cyberspace extended their learning beyond simply reading from a textbook. For instance, one student wrote that 'although I seldom really exchanged a dialogue with my peers on this site [elgg], however; by just following the thread of message posting and responding either from my course coordinator, tutors and peers I am able to make sense and understand the topics of discussion that help me in my own assignment...".

In terms of their opinions in comparing LMS to the elgg, the result was equally split across the student participants. In particular one of these students stated that the activity of looking for information related to the course, "... is quite structured and straightforward [in LMS] and I can easily look for the documents posted by my course coordinator more easily than searching on where the document is posted at the new platform [elgg]". Other comments were that elgg tool is a "great and effective way to help me connect to my study peers" and other comment was "the current [LMS] learning platform is much simpler and I am already used to it".

\section{Cooperative Learning}

Certain learning activities required students to use this platform to engage in conversation (threaded message posting, chat, etc.) to exchange ideas with their peers, such as commenting on individual course-related entries by encouraging students to suggest ways to improve it and to learn from each other. Effandi and Zanaton (2007) and Kan (2011) noted that the instructional method of cooperative learning is believed to be a learning process which is most effective when 
students are actively involved in sharing their ideas and work amongst themselves cooperatively to complete academic tasks. Essentially, this approach to learning creates excellent opportunities for students to engage in problem-solving with the help of the group and peer members (Kan, 2011). A few student participants stated that they really appreciated the elgg platform because they were able to setup their own group and form their own group members. One particular participant summarized that "cooperation from each group member is the main aspect to succeed in distance education because we cannot see or meet our group members regularly". Another similar comment was; "I become more independent on doing my assignment. I can understand more of what I had learned and through the chat feature I can chat with my friends about how to do the assignment and exchange ideas". One of the interesting comments was:

"I am able to experience the team/group-based learning where my peers in this course are helping each other out even we are from remote locations... furthermore, I think it helps to have a discussion blog that everybody contribute ideas and this helps me to complete my assignment faster..."

Anderson (2005) cited that cooperative activities are generally short term, bounded in a temporary period of time (such as an assignment or a project), such that learners can cooperate outside of the knowledge of where and in which order they are studying and consists of cooperation between those engaged in the class or those not formally enrolled in a program of studies. One student wrote that the experience "seem[s] cooperative and collaborative.... everybody was in there together... and best of all, no one [was] in there to order or instruct us, almost like you are your own instructor, quite refreshing and nice in a sense...even my wife was able to help me to take notes on the discussion [thread notes] during one of the study discussions".

Some participants expressed a preference of elgg over the traditional course management system. One student noted that "...elgg was the newest thing I have come across and I really liked the interface and features... offered by it... I can be collaborating with my peers in less formal ways". The negative experiences noted by some of the students were regarding particular features and congregated around issue of the problematic platform. In particular, students who had negative remarks on the platform stated complaints such as: "[The] lack of technical support and troubleshooting" when they encountered errors. One student commented that "In LMS, I am able to send email to my peers but this new platform I don't see that it has the features and function to do so". Another suggested that the platform site gets "cluttered and [I] have difficulty ...look[ing] for the latest discussion thread".

\section{Appreciation of Differences of Opinion}

The last theme gathered from the survey responses was that several students expressed that the elgg platform enabled them to understand the range of opinions of other students when working on activities or assignments, and felt that it had enhanced their perspectives. Due to the nature of the course (Human Resource Management), the activities and assignments presented were always descriptive and often asked open-ended questions that encouraged students to read and to comprehend "off the textbook" content in order to form an answer to the question. Students were given a serious online activity that involved the use of blogs in the form of threaded 
discussions and they were asked to invite their peers to make comments on the course's human resource issues. Lim, Cheung and Hew (2011) contend that the asynchronous online forum has become a primary focus of educational researchers. They hypothesize that the process of typing out messages (such as in an online forum discussion) in and of itself, can promote in-depth critical thinking skills, showing an appreciation of diversity of ideas, and thus enhance students' skills and knowledge. One of the powerful aspects of a blog is that all of the contributions and entries from a previous person is recorded and students comments from the daily activities are invaluable, providing insights and perspectives that would be difficult to obtain in face-to-face classes because it would be practically impossible to hear more than 30 comments about each topic from each student. Also, having the comments in a written format allows students to go back and discuss in even greater detail later. For example, one particular participant commented:

"What I enjoyed about this course [elgg] was that all my peers are working adult learners like myself. We all come with different walk of life and each one of us carries their own knowledge and skills set which good to have diverse opinions and contribute different perspective in working on assignment."

Numerous student participants shared a concern that while working through a community-based approach seemed appealing and beneficial in some ways; students also noted that reading through individual blogs can be quite time-consuming. Some students worried that this course would take more time than they anticipated, based on their experience with other distance courses. For instance, one student wrote on the survey feedback that "..I enjoy reading my peers' blogs and the activities posted, I am taking two other distance courses at the same time, and I find that I do not have enough time to do what I needed to do..." One student shared that they were "not sure what is the focus here as we have two platforms [LMS and elgg] required for this course, I find it quite redundant to use both as it is not only take up my time [to look up information] and would really appreciate give the simpler version... though I do like the feature of the new learning platform [elgg] provided that I can shared and discuss opinions with my peers".

\section{Implications}

Findings from this study further reinforce the results of previous studies done regarding the use of social networking tools in educational settings. The majority of the participants in this research project indicated they did enjoy the social learning experience afforded by the elgg when compared to LMS to support one another in their distance learning experiences. It was also noted that participants exhibited high involvement in graded exercises in most cases, and would share information only at the level required by the instruction mode. Brady, Holcomb, and Smith (2010) noted that it is difficult to establish a community of practice in distance education and its establishment cannot be forced, even when using media that lend themselves to high levels of engagement. The authors further commented that students may need more time [than a semester] to feel comfortable with using the mode and become empowered and adapted to being a part of the community of practice. Nevertheless, participants for this study generally noted that they perceived their learning experience was enhanced by their interaction with each other and the instructors. 
The three key emergent themes, noted earlier, further supports previous studies on the promise of integrating and using social networking technology as a distance learning platform (Brady, Holcomb, \& Smith, 2010; Dron \& Anderson, 2009; Oradini \& Saunders, 2008; Siemens \& Conole, 2011; Veletsionos \& Navarrete, 2012). The social connectivism pedagogy perhaps can be used as a guide when applying social and digital technology tools to create learning communities that facilitate more interaction between students to gain knowledge. The untold beauty of incorporating social media tools is that the flexibility and immediacy makes this form of teaching and learning more appealing to present-day learners, both the "digital native" and the "digital immigrant". The incoming learners are people who might have become accustomed to social media as they may already communicate often using social media and learn in a different way than the generation before them. Thomas and Thomas (2011) noted that "teaching methods and styles adopted previously are likely to be outmoded... recognizing that social media is a requirement for modern day business". The authors also posited that future research about facilitating tomorrow's learners is likely focus on the impact of social media beyond the immediate learning environment.

New technologies brought by the invention of Web 2.0 and the social networking applications seem to have given distance learners opportunities to practice 21st-century skills in collaboration, sharing knowledge and to develop critical thinking skills (Siemens, 2010). As Hoffman (2010) stated: "The potential for loosening institutional controls over tool access, the rapid growth of social networking beyond college walls, and the decreasing costs for user training and readyavailability are suggestive that these new tools will spread like earlier innovations such as word processing and email as foundational tools for higher education". These new tools allow greater flexibility in designing environments rather than being stuck with content-focused containers, which fosters better and more personalized learning --an ideal situation for distance learners.

\section{Conclusion}

Social networking provides a vital source of information and numerous opportunities for participants to build social capital that aims at improving their learning. No doubt those popular social networking sites have gained wide interest from the educational industries in capitalize on its potential to improve student engagement and learning. Furthermore, the ODL mode of learning is on the rise across the globe. In this study, a social networking platform enriched by elgg was employed as an additional learning medium for students and tutors. The results indicated that students and tutors did enjoy the social learning experience afforded by the elgg; however, it should also be noted that students' involvement was limited only to course-related work and graded exercises. Additionally, the study observed that students may need more time when employing this technology and organizations should provide sufficient technical support for them to feel more comfortable in the community of practice.

While this study focuses on one particular country's ODL learners learning experience, it offers some insights and explanations. Perhaps similar future studies may expand and generalize understanding about social networking tools regarding improving student learning experiences. The future studies could focus more on how the flexibility and immediacy makes this form of techno-echo and social- echo in learning more appealing to present-day distance learners who 
might have come to the learning environment already accustomed to social media. Additionally, the recommendation for future study on this topic should be extended to a larger group of learners from various courses and disciplines, inclusive of perspectives from the instructors and educational technologists to help expand understanding in this area.

\section{References}

Anderson, T. (2005). Distance learning-Social software's killer ap? Retrieved on 25 September 2012 from http://auspace.athabascau.ca/handle/2149/2328.

Brady, K.P., Holcomb, L.B., \& Smith, B.V. (2010). The use of alternative social networking sites in higher educational settings: a case study of the e-learning benefits of Ning in education. Journal of Interactive Online Learning. 9(2), 151 -170.

Doering, A. \& Veletsianos, G. (2008). Hybrid online education: Identifying integration models using adventure learning. Journal of Research on Technology in Education, 41(1), 101 -119.

Dron, J. \& Anderson, T. (2009). Lost in social space: Information retrieval issues in Web 1.5. Journal of Digital Information, 10(2), 1 -12

Effandi, Z. \& Zanaton, I. (2007). Promoting cooperative learning in science and mathematics education: A Malaysia Perspective. Eurasia Journal of Mathematics, Science \& Technology Education, 3(1), 35-39.

Garrison, R., Anderson, T., \& Archer, W. (2000). Critical inquiry in a text-based environment: Computer conferencing in higher education. The Internet and Higher Education, 2(2), 87-105.

Hoffman, E. (2010). Social media and learning environments: Shifting perspectives on the locus of control. Retrieved on 25 September 2012 from http://www.ineducation.ca/article/Socialmedia-and-learning-environments-shifting-perspectives-on-the-locus-of-control.

Kan, O. (2011). Cooperative learning environment with the web 2.0 Tool e-Portfolios. Turkish Online Journal of Distance Education, 12(3), 201-213

Lim, S., Cheung, W., \& Hew, K. (2011). Critical thinking in asynchronous online discussion: A investigation of student facilitation techniques. New Horizons in Education. 59(1) 52-65

Olofsson, A. D. (2007). Participation in an educational online learning community. Educational Technology \& Society, 10(4), 28-38.

Oradini, F. \& Saunders, G. (2008). The use of social networking by students and staff in higher education. Paper presented at the iLearning Forum, 2008 in Paris. Retrieved on 25 September 2012 from http://www.eifel.org/publications/proceedings/ilf08/contributions/ improving-quality-of-learning-with-technologies/Oradini.pdf

Siemens, G. (2010). Connectivism. Retrieved on 25 September 2012 from http://connectivism. $\mathrm{ca} / \mathrm{p}=220$

Siemens, G. \& Conole, G. (2011). Special Issue - Connectivism: Design and delivery of social networked learning. The International Review of Research in Open and Distance Learning. 12(3), i-iv 
Thomas, M. \& Thomas, H. (2012). Using new social media and Web 2.0 technologies in business school teaching and learning. Journal of Management Development, 31(4), 358-367.

Veletsianos, G (2010). A definition of emerging technologies for education. In G. Veletsianos (Ed.), Emerging technologies in distance education (pp.3-22). Edmonton, AB: Athabasca University Press.

Veletsianos, G. \& Navarrete, C. (2012). Online social networks as formal learning environments: Learner experiences and activities. The International Review of Research in Open and Distance Learning, 13(1), 144-166.

Wankel, C. (2009). Management education using social media. Organisation Management Journal, 6(6), 251-262.

Correspondence: Lai Cheng Tung, Course Coordinator, School of Business and Administration, Wawasan Open University, George Town, Penang, Malaysia. 